\title{
Influence of System Layout on CM EMI Noise of SiC Electric Vehicle Powertrains
}

\author{
Xiaoyu JIA, Changsheng HU, Bitao DONG, Fengchun HE, Hui WANG, and Dehong XU
}

\begin{abstract}
This paper investigates the influences of system layout on common mode (CM) EMI noise of an electric vehicle (EV) powertrain with a traction inverter using silicon carbide $(\mathrm{SiC})$ MOSFETs. First, a system level conducted EMI model for the whole $\mathrm{SiC} \mathrm{EV}$ powertrain is presented, which includes a battery pack, DC cables, a SiC inverter, AC cables, and a PMSM. Then, the impacts of system layout, such as the $\mathrm{AC}$ cable length, the $\mathrm{AC}$ cable type, and the DC cable type (shielded cable and unshielded cable) on CM EMI noise are analyzed through time domain simulations of the system level conducted EMI model. Next, a conducted EMI emission test-bed for a $\mathrm{SiC} \mathrm{EV}$ powertrain is built. Finally, experiments on the test-bed are carried out to verify the influences of system layout on CM EMI noise in the SiC EV powertrain.
\end{abstract}

Index Terms - Cable, common mode (CM) electromagnetic interference (EMI), electric vehicle (EV) powertrain, silicon carbide (SiC) MOSFET, system layout.

\section{INTRODUCTION}

$\mathrm{D}^{\mathrm{s}}$ UE to outstanding performance of wide-band-gap (WBG) devices such as higher switching speed and smaller loss, it can reduces the size of the powertrain and increases the mileage of electric vehicles (EVs) [1]-[4]. Therefore, development of inverters with WBG devices for EVs becomes a hot topic recently. Although inverters with silicon carbide (SiC) MOSFETs have been used in Tesla car and other products [5], [6], electromagnetic interference (EMI) issues of SiC MOSFETs' high switching frequency and high $\mathrm{d} v / \mathrm{d} t$ are still concern.

In an EV powertrain, the inverter operates under PWM control, the inverter AC terminal potentials vary between the positive and negative rails of the DC bus, leading to high frequency step-like common-mode (CM) voltage source waveforms with a high value of $\mathrm{d} v / \mathrm{d} t$. The CM voltage source not only drives leakage current into the ground system (vehicle frame) due to parasitic capacitance in the powertrain (i.e. battery, inverter, cables, and traction motor) [7]-[9], which may induce EMI noise to various electronic devices and equipment in the car [10]. System layout determines many parasitic

Manuscript received December 2, 2020; revised January 23, 2021; accepted February 5, 2021. Date of publication December 30, 2021; date of current version December 24, 2021. (Corresponding authors: Dehong Xu and Changsheng Hu.)

All authors are with the College of Electrical Engineering, Zhejiang University, Hangzhou, 310027, China (e-mail: xiaoy jia@zju.edu.cn; hucs@zju.edu.cn; 3150101341@zju.edu.cn; frankie0123@163.com; 21810036@zju.edu.cn; xdh@ zju.edu.cn).

Digital Object Identifier 10.24295/CPSSTPEA.2021.00028 parameters, impacts CM EMI noise propagation paths, and influences system CM EMI noise.

The modelling and suppression of conducted emission of $\mathrm{SiC} \mathrm{EV}$ powertrains have been investigated by predecessors. Their works can be classified into three categories. First category of papers studied the noise source characteristics of $\mathrm{SiC}$ inverters. The EMI noise source of $\mathrm{SiC}$ inverters has three features in comparison to that of IGBT inverters. First, $\mathrm{SiC}$ inverters generate higher EMI noise for they work at a higher switching frequency [11], [12]. Second, the high $\mathrm{d} v / \mathrm{d} t$ of SiC inverters, up to ten times higher than that of IGBT inverters, causes high EMI noise in powertrains [13], [14]. Lastly, serious switching ringing in the SiC MOSFET turn-off process causes extra EMI noise in powertrains [12], [15].

The second category of papers investigated EMI noise transmission paths. Noise transmission paths include cables, motors, etc. Permanent magnet synchronous motor (PMSM) EMI model is derived by either measurement [16], [17] or analytical model according to electric machine theory [18], [19]. The measurement based model is practical and useful for motor drive EMI simulation, but the physical meaning of the circuit is not clear. The analytical model has a clear physical meaning, and circuit parameters are estimated by numerical formulae or by electromagnetic field analysis. For an EV powertrain with a certain PMSM, the setup of cables impacts the EMI noise propagation paths and system conducted emission [20]-[25]. The effects of long cable on motor overvoltage and conducted emission problem have been studied in adjustable speed drive [20], [21]. In [22], the equivalent circuit model of the return paths of CM EMI noise currents in EV powertrain is proposed. The CM current return paths include braided shield of three-phase cables and the metallic vehicle body. In [23], an analytical approach to obtain the shield and ground currents as a function of the inner conductor current is presented to quantify the current distribution between the shield and the ground. In [24], the impact of connecting and disconnecting the shield terminals of the DC power bus on the line impedance stabilization network (LISN) voltage and the CM current is presented. In [25], the effects of separately shielded cables and cables with a total shield for three phases on the emission in EV powertrains are studied in time and frequency domain. The separately shielded cables achieve worse results.

The third category of papers tried to suppress EMI noise in the system. Filtering technique, cancelling technique, and balance 


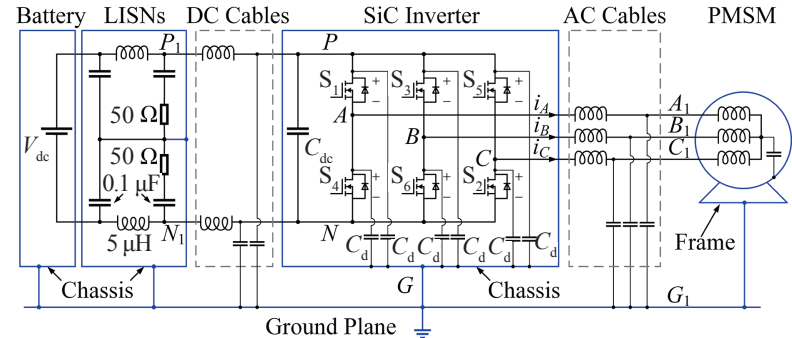

Fig. 1. A diagram of conducted emission test setup of an EV powertrain.

technique for conducted EMI noise reduction have been reported in the literature. Filtering technique refers to the use of passive filters which are inserted to the converter system to block or bypass EMI noise [7], [26]. Cancelling technique usually refers to the use of active EMI filters which generate a current/voltage to cancel with EMI noise [27], [28]. Balance technique refers to the creation of a Wheatstone impedance bridge by adding several passive components to the system [29], [30].

As mentioned above, although the noise characteristics of a $\mathrm{SiC}$ inverter have been studied, the modelling of noise transmission paths, and the EMI noise suppression of motor drive system have been published in the literature. A study on the impacts of system layout, such as AC cable length, AC and DC cable type (shielded cables and unshielded cables) on CM EMI noise of SiC EV powertrains is needed through both theoretical analysis and experimental results. This paper investigates the influences of system layout on CM EMI noise of a SiC EV powertrain. First, a system-level conducted EMI model for the whole powertrain is presented. Based on this model, the impacts of AC cable length, AC and DC cable type on CM EMI noise are discussed. Finally, experiments on a conducted EMI test-bed are carried out to verify the influences of the system layout on CM EMI noise in a SiC EV powertrain.

\section{System-LeVel Conducted EMI Model}

Fig. 1 shows a diagram of the conducted emission test setup of an EV powertrain, which includes a battery pack, LISNs, DC cables, a SiC inverter, AC cables, and a PMSM. The battery pack chassis, LISN chassis, inverter chassis, and frame of the PMSM are connected to the ground plane for safety consideration.

In CM noise analysis, lower switches are replaced by voltage sources $v_{\mathrm{AN}}, v_{\mathrm{BN}}$, and $v_{\mathrm{CN}}$. The positive DC terminal $P$ and the negative DC terminal $N$ are considered as short-circuited because the inverter DC voltage is almost fixed by using a bulk capacitor $C_{\mathrm{dc}}$. As a result, each of the upper switches is in parallel with the lower switch. Assuming that parameters of the positive DC line are the same as the negative line, CM currents in the positive and the negative DC lines are the same. Hence, LISNs terminals of node $P_{1}$ and node $N_{1}$ can be short-circuited. In the $\mathrm{AC}$ side, the PWM modulation for a three-phase inverter is symmetric, namely $v_{\mathrm{AN}}, v_{\mathrm{BN}}$ and $v_{\mathrm{CN}}$ are shifted $120^{\circ}$ between each other. In this case, node $A$, node $B$, and node $C$ can be short-circuited in $\mathrm{CM}$ analysis because $\mathrm{CM}$ components of $v_{\mathrm{AN}}, v_{\mathrm{BN}}$ and $v_{\mathrm{CN}}$ are the same, which is derived in detail in the

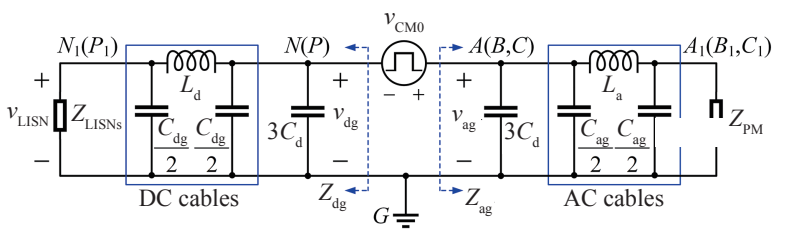

Fig. 2. A simplified CM EMI model of an EV powertrain.

Appendix-A. Assuming that parameters of phase $A$, phase $B$, and phase $C$ are the same, CM currents in the three phases are the same. As a result, PMSM terminals of node $A_{1}$, node $B_{1}$, and node $C_{1}$ can be short-circuited. In addition, DC cables and AC cables are modeled as $\pi$-type lumped circuits, $L_{\mathrm{d}}$ and $C_{\mathrm{dg}}$ are the equivalent inductance and capacitance of DC cables, $L_{\mathrm{a}}$ and $C_{\text {ag }}$ are the equivalent inductance and capacitance of AC cables. The CM model of the system is simplified and shown in Fig. 2. $Z_{\text {LISNs }}$ is the impedance of the LISNs, which can be calculated through the circuit of LISN in Fig. 1. $Z_{\mathrm{PM}}$ is the CM impedance of the PMSM, which is obtained by measurement. It should be noticed that the distributed parameter effect is ignored in the simplified CM EMI model. According to the transmission line theory, this lumped circuit model for cables is suitable when the cable length $l$ is electrically short at the excitation frequency, generally $l<\lambda / 10$. In the prototype, it can be derived that the lumped circuit model can be used in the frequency lower than $10 \mathrm{MHz}$ for DC cable is $1.8 \mathrm{~m}$ and $\mathrm{AC}$ cable is $1.6 \mathrm{~m}$ in the prototype.

The CM noise source $v_{\mathrm{CM} 0}$ in Fig. 2 is defined as follows [32]:

$$
v_{\text {СM0 }}=\frac{v_{\mathrm{AN}}+v_{\mathrm{BN}}+v_{\mathrm{CN}}}{3}
$$

According to the circuit theory, CM LISN voltage $v_{\text {LISN }}$ is expressed as follows:

$$
V_{\text {LISN }}=-A_{\mathrm{d}} \frac{Z_{\mathrm{dg}}}{Z_{\mathrm{dg}}+Z_{\mathrm{ag}}} V_{\text {CM0 }}
$$

where $V_{\text {LISN }}$ and $V_{\text {CM0 }}$ are the Laplace transformation of $v_{\text {LISN }}$ and $v_{\mathrm{CM} 0}$, respectively. The AC impedance $Z_{\mathrm{ag}}$, the $\mathrm{DC}$ impedance $Z_{\mathrm{dg}}$, and the voltage ratio $A_{\mathrm{d}}$ from $V_{\mathrm{LISN}}$ to $V_{\mathrm{dg}}$ are expressed as follows:

$$
\left\{\begin{array}{l}
Z_{\mathrm{ag}}=\frac{1}{s\left(3 C_{\mathrm{d}}+\frac{C_{\mathrm{ag}}}{2}\right)} / /\left(s L_{\mathrm{a}}+Z_{\mathrm{PM}} / / \frac{1}{C_{\mathrm{ag}}}\right) \\
Z_{\mathrm{dg}}=\frac{1}{s\left(3 C_{\mathrm{d}}+\frac{C_{\mathrm{dg}}}{2}\right)} / /\left(s L_{\mathrm{d}}+Z_{\mathrm{LISNs}} / / \frac{1}{C_{\mathrm{dg}}}\right) \\
A_{\mathrm{d}}=\frac{V_{\mathrm{LISN}}}{V_{\mathrm{dg}}}=\frac{Z_{\mathrm{LISNs}} / / \frac{1}{s \frac{C_{\mathrm{dg}}}{2}}}{s L_{\mathrm{d}}+Z_{\mathrm{LISNs}} / / \frac{1}{C_{\mathrm{dg}}}}
\end{array}\right.
$$


TABLE I

Equivalent Inductance and Capacitance of DC and AC Cables

\begin{tabular}{lccccc}
\hline \hline \multirow{2}{*}{ Item } & \multirow{2}{*}{ Symbol } & \multicolumn{2}{c}{ Shielded cable } & \multicolumn{2}{c}{ Unshielded cable } \\
& & Expression & Value & Expression & Value \\
\hline DC & $L_{\mathrm{d}}$ & $l_{\mathrm{d}} \frac{L_{\mathrm{c}}-L_{\mathrm{s}}}{2}$ & $51.8 \mathrm{nH}$ & $l_{\mathrm{d}} \frac{L_{\mathrm{c}}+L_{\mathrm{m}}}{2}$ & $848.3 \mathrm{nH}$ \\
cable & $C_{\mathrm{dg}}$ & $2 l_{\mathrm{d}} C_{\mathrm{cs}}$ & $1.5 \mathrm{nF}$ & $2 l_{\mathrm{d}} C_{\mathrm{cg}}$ & $60.7 \mathrm{pF}$ \\
& $L_{\mathrm{a}}$ & $l_{\mathrm{d}} \frac{L_{\mathrm{c}}-L_{\mathrm{s}}}{3}$ & $30.7 \mathrm{nH}$ & $l_{\mathrm{d}} \frac{L_{\mathrm{c}}+2 L_{\mathrm{m}}}{3}$ & $727.2 \mathrm{nH}$ \\
$\begin{array}{l}\text { AC } \\
\text { cable }\end{array}$ & $C_{\mathrm{ag}}$ & $3 l_{\mathrm{d}} C_{\mathrm{cs}}$ & $2.0 \mathrm{nF}$ & $3 l_{\mathrm{d}} C_{\mathrm{cg}}$ & $80.9 \mathrm{pF}$ \\
\hline \hline
\end{tabular}

The per unit length (p.u.l) parameters of DC and AC cables are provided in detail in the Appendix-B. The equivalent inductances and capacitances of DC and AC cables are listed in Table I, which are derived in detail in the Appendix-C. $L_{\mathrm{c}}$ is the p.u.l self-inductances of the cable core. $L_{\mathrm{s}}$ is the p.u.l selfinductances of the shield for shielded cables. $L_{\mathrm{m}}$ is the p.u.l mutual inductance between cores of one cable and another one. $C_{\mathrm{cs}}$ is the p.u.l capacitance between the core and the shield for shielded cables. $C_{\mathrm{cg}}$ is the p.u.l capacitance between the core and the ground plane for unshielded cables. $l_{\mathrm{d}}$ and $l_{\mathrm{a}}$ are the lengths of DC and $\mathrm{AC}$ cables, respectively. According to formulas in Table I and expression of $L_{\mathrm{c}}, L_{\mathrm{s}}, L_{\mathrm{m}}, C_{\mathrm{cs}}$, and $C_{\mathrm{cg}}$ in the Appendix-B, it can be seen that the equivalent inductance of shielded cables is much smaller than that of unshielded cables, whereas the equivalent capacitance of shielded cables is much larger than that of unshielded cables. This is more intuitive when we compare the values in Table I.

For the reason that $v_{\mathrm{CM} 0}$ in (1) is mainly determined by the characteristics of the $\mathrm{SiC}$ MOSFET, the gate drive circuit, and the parasitic parameters of the commutation loop [33], and has little relationship with DC and AC cable type. Hence, the amplitude of $V_{\text {LISN }} / V_{\text {СM0 }}$ can be used to compare LISN voltages of systems with different types of cables. Fig. 3(a) shows the amplitude of $V_{\mathrm{LISN}} / V_{\mathrm{CM} 0}$ of a system with shielded DC and AC cables and a system with shielded DC cables and unshielded AC cables. Fig. 3(b) shows the amplitude of $V_{\text {LISN }} / V_{\text {CM0 }}$ of a system with unshielded DC cables and shielded $\mathrm{AC}$ cables and a system with unshielded DC and AC cables. It can be seen that no matter shielded DC cables or unshielded DC cables are used, CM LISN voltage of the system with unshielded AC cables has low harmonics. Fig. 3(c) shows the amplitude of $V_{\text {LISN }} / V_{\text {CM0 }}$ of a system with shielded $\mathrm{DC}$ and $\mathrm{AC}$ cables and a system with unshielded DC cables and shielded AC cables. Fig. 3(d) shows the amplitude of $V_{\text {LISN }} / V_{\text {CM0 }}$ of a system with shielded DC cables and unshielded $\mathrm{AC}$ cables and a system with unshielded DC and AC cables. It can be seen that if shielded AC cables are used, CM LISN voltage of the system with unshielded DC cables has low harmonics. If unshielded AC cables are used, CM LISN voltage of the system with unshielded DC cables has low harmonics in one frequency range, but has high harmonics in another frequency range. Based on the analysis above, unshielded DC cables are used while shielded AC cables are used.

Theoretical analysis based on the simplified CM EMI model

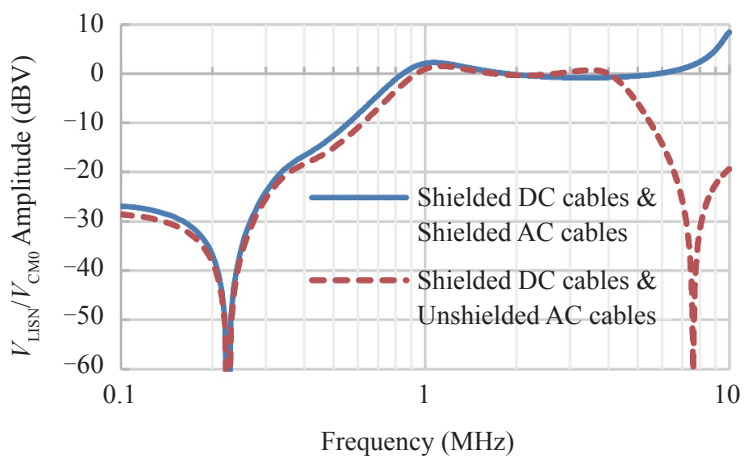

(a)

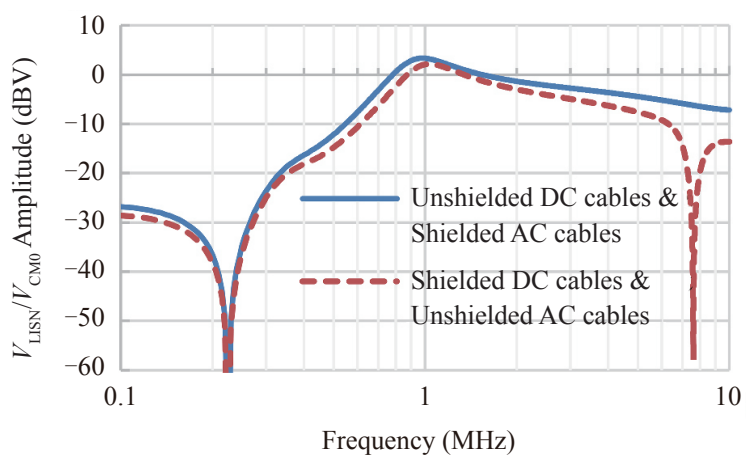

(b)

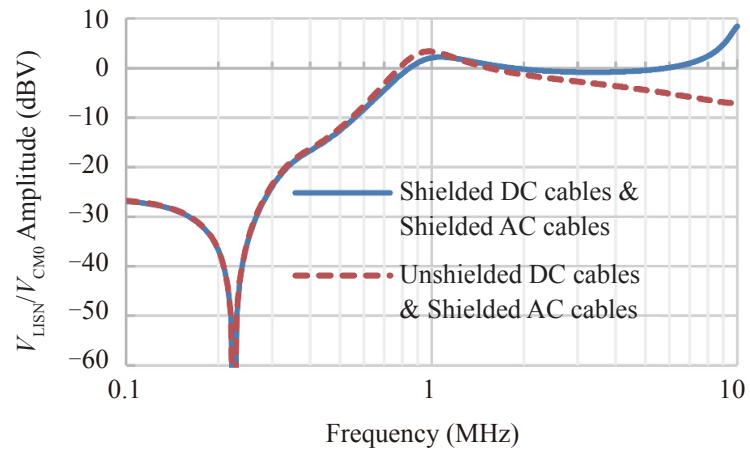

(c)

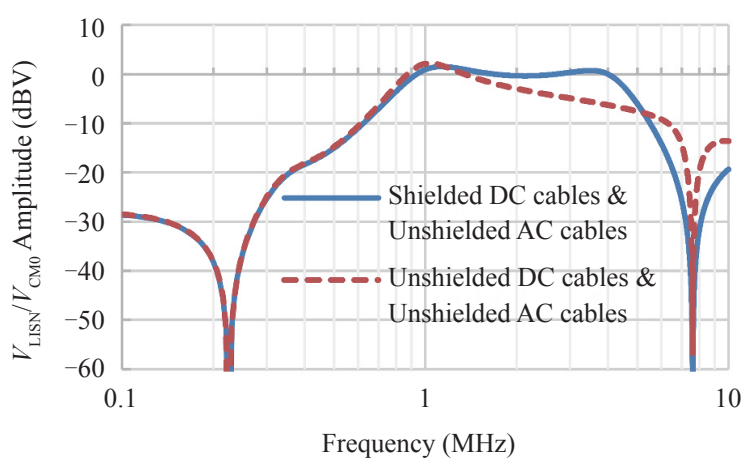

(d)

Fig. 3. The amplitude of $V_{\mathrm{LISN}} / V_{\mathrm{CM} 0}$ vs. cable type (a) a system with shielded DC and AC cables vs. a system with shielded DC cables and unshielded AC cables, (b) a system with unshielded DC cables and shielded AC cables vs. a system with unshielded DC and AC cables, (c) a system with shielded DC and $\mathrm{AC}$ cables vs. a system with unshielded $\mathrm{DC}$ cables and shielded AC cables, and (d) a system with shielded DC cables and unshielded AC cables vs. a system with unshielded DC and AC cables. 


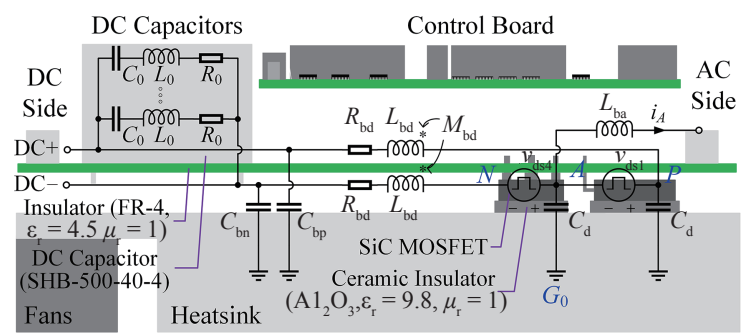

Fig. 4. A SiC inverter structure [31].

TABLE II

PARAmeters OF THE INVERTER [31]

\begin{tabular}{lccc}
\hline \hline Component & Item & Symbol & Quantity \\
\hline & Self-inductance & $L_{\mathrm{bd}}$ & $27.8 \mathrm{nH}$ \\
Laminated & Mutual inductance & $M_{\mathrm{bd}}$ & $19.8 \mathrm{nH}$ \\
DC busbar & Resistance (@ 100 MHz) & $R_{\mathrm{bd}}$ & $45.0 \mathrm{~m} \Omega$ \\
& Capacitance of DC+ to the heatsink & $C_{\mathrm{bp}}$ & $6.2 \mathrm{pF}$ \\
& Capacitance of DC- to the heatsink & $C_{\mathrm{bn}}$ & $25.3 \mathrm{pF}$ \\
AC busbar & Self-inductance & $L_{\mathrm{ba}}$ & $11.9 \mathrm{nH}$ \\
SiC MOS & Capacitance of drain to the heatsink & $C_{\mathrm{d}}$ & $119.5 \mathrm{pF}$ \\
DC capacitor & Capacitance & $C_{0}$ & $39.7 \mu \mathrm{FF}$ \\
(4 in parallel) & ESL & $L_{0}$ & $6.8 \mathrm{nH}$ \\
& ESR & $R_{0}$ & $5.8 \mathrm{~m} \Omega$ \\
\hline \hline
\end{tabular}

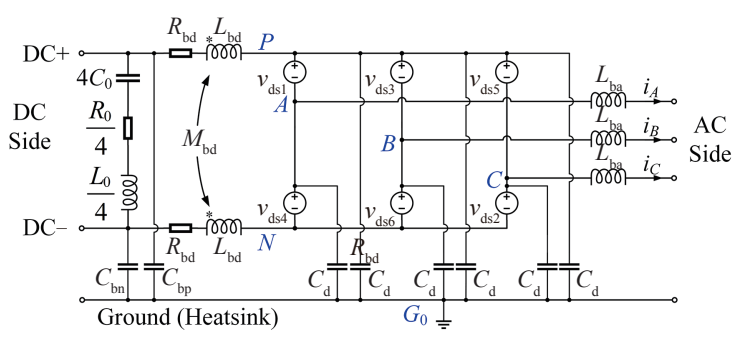

Fig. 5. An inverter EMI model [31].

shows that systems with different types of DC and AC cables have big differences in CM LISN voltages. However, it is difficult to predict the spectrum of CM LISN voltage accurately since parasitic parameters of the $\mathrm{SiC}$ inverter and distribution parameter effect of cables are ignored. Here, an accurate system-level EMI model based on parameter extraction is introduced for discussing influences of system layout, such as cable length and cable type on CM LISN voltage.

\section{A. Inverter Model}

Fig. 4 shows an inverter structure [31], which is made up of 3-phase SiC MOSFET inverter bridges and DC capacitors with low equivalent series inductance and resistance (ESL, ESR). The parasitic parameters of the laminated DC busbar, the AC busbar, and the SiC MOSFETs are extracted by ANSYS Q3D, whereas the parameters of DC capacitors are measured by an E4990A impedance analyzer from Keysight. These parameters are listed in Table II [31]. Fig. 5 shows the inverter EMI model [31]. The drain-source voltages of the SiC MOSFETs are modeled as trapezoidal voltage sources [13].

The rise time and fall time of the trapezoidal voltage sources in

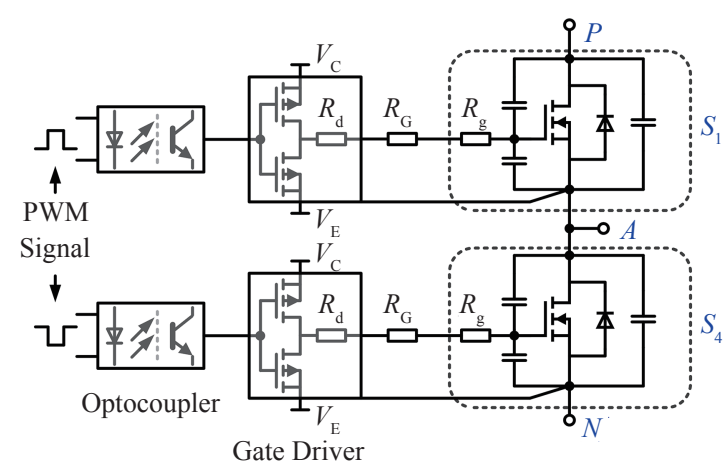

Fig. 6. A diagram of the gate drive circuit for a $\mathrm{SiC}$ inverter bridge.

TABLE III

Parameters of the Gate Drive Circuit

\begin{tabular}{lcc}
\hline \hline Item & Symbol & Quantity \\
\hline Driving voltage & $V_{\mathrm{C}} / V_{\mathrm{E}}$ & $+18 /-5 \mathrm{~V}$ \\
External gate resistance & $R_{\mathrm{G}}$ & $2.5 \Omega$ \\
SiC MOS internal gate resistance & $R_{\mathrm{g}}$ & $1.1 \Omega$ \\
Gate driver output resistance & $R_{\mathrm{d}}$ & $0.4 \Omega$ \\
\hline \hline
\end{tabular}

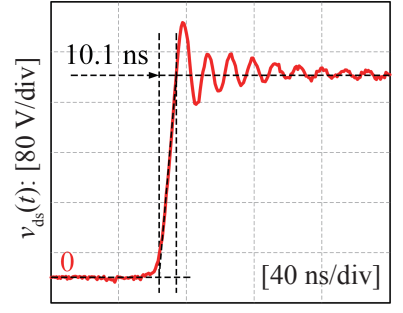

(a)

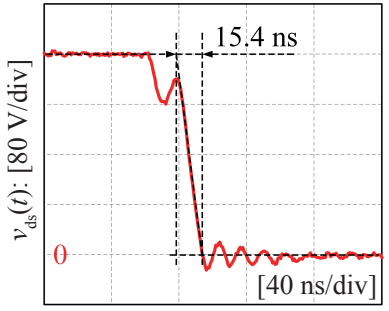

(b)
Fig. 7. Experimental drain-source voltages of a SiC MOSFET when DC voltage is $320 \mathrm{~V}$ and drain current is $60 \mathrm{~A}$ (a) turn-off, and (b) turn-on.

Fig. 4 and 5 are obtained through measurements on a classical double-pulse-test platform. A SiC MOSFET C2M0025120D from Wolfspeed is selected for experiments. A diagram of the gate drive circuit for a $\mathrm{SiC}$ inverter bridge is shown in Fig. 6. The gate drive circuit contains the digital optocouplers and the gate drivers (IXDI614YI). The driving voltage and the gate resistance are listed in Table III. Waveforms of the SiC MOSFET drain-source voltage $v_{\mathrm{ds}}(t)$ are obtained when DC voltage is $320 \mathrm{~V}$ and drain current is $60 \mathrm{~A}$. Fig. 7(a) and (b) show test results of $v_{\mathrm{ds}}(t)$ in the turn-off and turn-on process, respectively. The rise time of $v_{\mathrm{ds}}(t)$ is $10.1 \mathrm{~ns}$, and the fall time of $v_{\mathrm{ds}}(t)$ is $15.4 \mathrm{~ns}$.

\section{B. Cable Model}

Fig. 8 shows a setup of shielded cables and unshielded cables for DC and AC connections according to CISPR 25, 2016 [34]. The p.u.l parasitic parameters of shielded cables and unshielded cables are extracted by ANSYS Q3D and listed in Table IV.

The frequency range of conducted emission of $\mathrm{EV}$ powertrain by voltage method is $150 \mathrm{kHz}-108 \mathrm{MHz}$ [34]. The minimum 


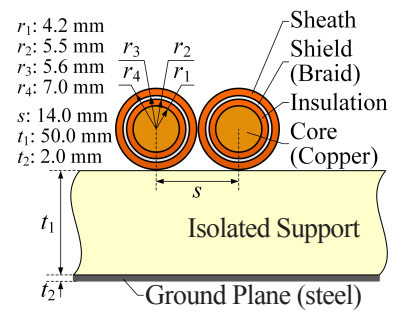

(a)

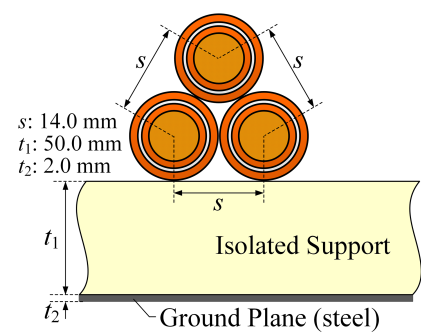

(c)

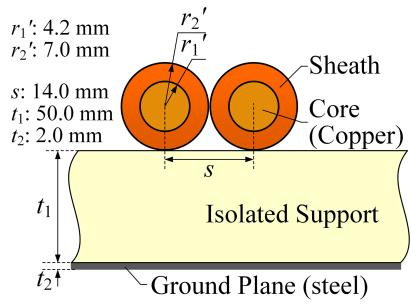

(b)

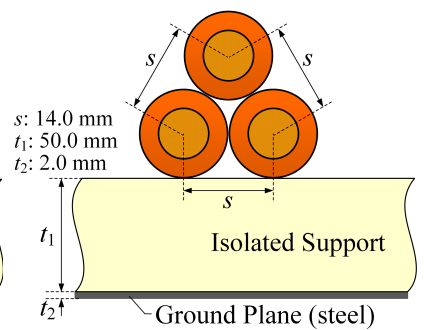

(d)
Fig. 8. A setup of the DC cables and AC cables (a) shielded DC cables, (b) unshielded DC cables, (c) shielded AC cables, and (d) unshielded AC cables.

TABLE IV

Parasitic Parameters of the Cables

\begin{tabular}{|c|c|c|c|}
\hline Type & Item & Symbol & Quantity \\
\hline \multirow{10}{*}{ Shielded } & Self-inductance of a core & $L_{\mathrm{c}}$ & $583.3 \mathrm{nH} / \mathrm{m}$ \\
\hline & Self-inductance of a shield & $L_{\mathrm{s}}$ & $531.5 \mathrm{nH} / \mathrm{m}$ \\
\hline & $\begin{array}{l}\text { Mutual inductance of a core and its } \\
\text { shield }\end{array}$ & $L_{\mathrm{cs}}$ & $531.4 \mathrm{nH} / \mathrm{m}$ \\
\hline & $\begin{array}{l}\text { Mutual inductance of cores/shields } \\
\text { of one cable and another cable }\end{array}$ & $L_{\mathrm{m}}$ & $385.9 \mathrm{nH} / \mathrm{m}$ \\
\hline & Capacitance of a core and its shield & $C_{\mathrm{cs}}$ & $482.8 \mathrm{pF} / \mathrm{m}$ \\
\hline & $\begin{array}{l}\text { Capacitance of shields of one cable } \\
\text { and another cable }\end{array}$ & $C_{\mathrm{ss}}$ & $47.8 \mathrm{pF} / \mathrm{m}$ \\
\hline & Capacitance of shield and the ground & $C_{\mathrm{sg}}$ & $19.1 \mathrm{pF} / \mathrm{m}$ \\
\hline & Resistance of a core $(100 \mathrm{MHz})$ & $R_{\mathrm{c}}$ & $0.26 \Omega / \mathrm{m}$ \\
\hline & Resistance of a shield (100 MHz) & $R_{\mathrm{cs}}$ & $0.11 \Omega / \mathrm{m}$ \\
\hline & Resistance of the ground $(100 \mathrm{MHz})$ & $R_{\mathrm{g}}$ & $0.024 \Omega / \mathrm{m}$ \\
\hline \multirow{6}{*}{$\begin{array}{l}\text { Un- } \\
\text { shielded }\end{array}$} & Self-inductance of a core & $L_{\mathrm{c}}^{\prime}$ & $610.0 \mathrm{nH} / \mathrm{m}$ \\
\hline & Mutual inductance of cores & $L_{\mathrm{m}}^{\prime}$ & $388.6 \mathrm{nH} / \mathrm{m}$ \\
\hline & Capacitance between cores & $C_{\mathrm{cc}}^{\prime}$ & $31.9 \mathrm{pF} / \mathrm{m}$ \\
\hline & Capacitance of a core and the ground & $C_{\mathrm{cg}}^{\prime}$ & $18.3 \mathrm{pF} / \mathrm{m}$ \\
\hline & Resistance of a core $(100 \mathrm{MHz})$ & $R_{\mathrm{c}}^{\prime}$ & $0.16 \Omega / \mathrm{m}$ \\
\hline & Resistance of the ground (100 MHz) & $R_{\mathrm{g}}^{\prime}$ & $0.024 \Omega / \mathrm{m}$ \\
\hline
\end{tabular}

electromagnetic wavelength is:

$$
\lambda_{\text {min }}=\frac{v}{f_{\text {max }}}=\frac{1}{\sqrt{\mu \varepsilon} \cdot f_{\text {max }}} \approx 1.9 \mathrm{~m}
$$

where $v$ is the velocity of propagation of the waves on the lines, $\mu=\mu_{0}, \varepsilon=\varepsilon_{0} \varepsilon_{r}$ are the permeability and the permittivity of the surrounding medium, respectively $\left(\varepsilon_{r}=2.2\right.$ for the insulation).

The DC cables and AC cables are divided into small segments. The length of each segment $l$ is electrically short at the excitation frequency, generally $l<\lambda_{\min } / 10(0.19 \mathrm{~m})$. Hence the segments can be represented as lumped circuits. Finally, the length of each segment is set to $l=0.1 \mathrm{~m}$.

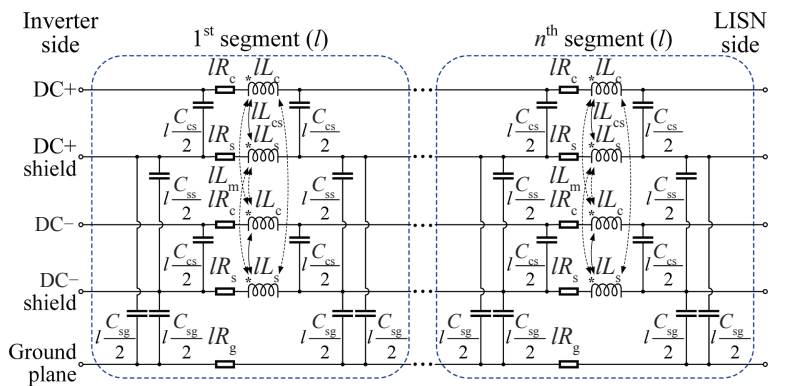

(a)

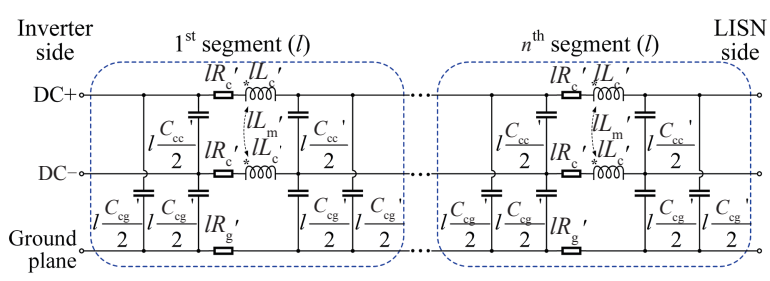

(b)

Fig. 9. DC cable EMI model (a) shielded DC cables, (b) unshielded DC cables.

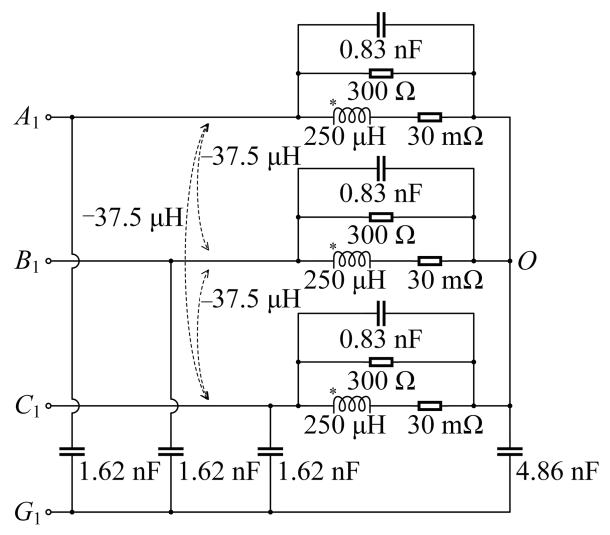

Fig. 10. An EMI model of the PMSM [31].

Fig. 9(a) and (b) show EMI models of shielded DC cables and unshielded DC cables, respectively. Similarly, EMI models of shielded and unshielded AC cables can be obtained.

\section{PMSM Model}

Fig. 10 shows a lumped-circuit model of a PMSM [31].

\section{System-Level Conducted EMI Model}

The system-level conducted EMI model is assembled from the models of components, including LISNs, DC cables, a $\mathrm{SiC}$ inverter, AC cables, and a PMSM. The couplings between components are ignored.

\section{Influence of System Layout on CM EMI Noise}

The influences of system layout, including AC cable length, AC cable type, and DC cable type on CM EMI noise are investigated according to the system-level EMI model. The parameters of the inverter operating point are listed in Table V. 
TABLE V

Conducted EMI Noise Test Conditions

\begin{tabular}{lll}
\hline \hline Item & Symbol & Quantity \\
\hline DC voltage & $V_{\mathrm{dc}}$ & $320 \mathrm{~V}$ \\
Fundamental AC line voltage & $V_{\mathrm{AB}}$ & $182 \mathrm{~V} \mathrm{rms}$ \\
Fundamental phase current & $I_{\mathrm{A}}$ & $40 \mathrm{~A} \mathrm{rms}$ \\
Fundamental frequency & $f_{\mathrm{o}}$ & $200 \mathrm{~Hz}$ \\
Switching frequency & $f_{\mathrm{s}}$ & $10 \mathrm{kHz}$ \\
\hline \hline
\end{tabular}

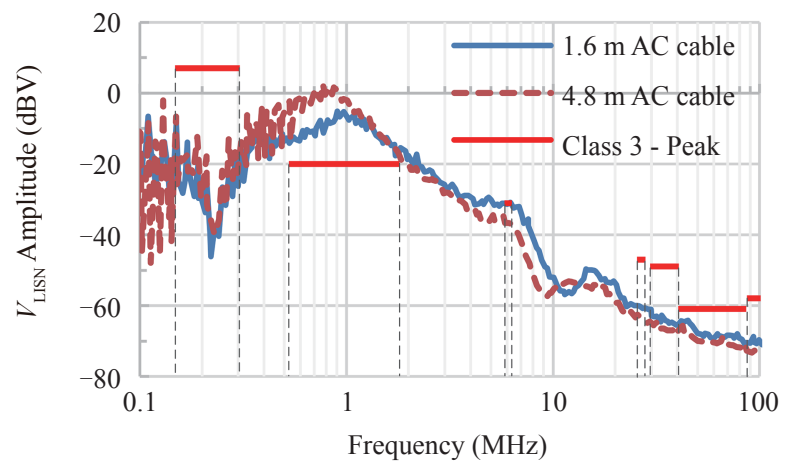

Fig. 11. Simulation amplitude spectral envelopes of $V_{\text {LISN }}$ of systems with $1.6 \mathrm{~m}$ and $4.8 \mathrm{~m}$ shielded AC cables.

The inverter operates under continuous SVPWM.

To investigate the influences of $\mathrm{AC}$ cable length on $\mathrm{CM}$ EMI noise of the SiC EV powertrain, circuit simulations in time domain for systems with $1.6 \mathrm{~m}$ and $4.8 \mathrm{~m}$ shielded $\mathrm{AC}$ cables are carried out, respectively. A bunch of $1.8 \mathrm{~m}$ shielded DC cables is used in the system. For discussing the impacts of AC cable type on system CM EMI noise, systems with $1.6 \mathrm{~m}$ shielded $\mathrm{AC}$ cables and $1.6 \mathrm{~m}$ unshielded $\mathrm{AC}$ cables are simulated, respectively. A bunch of $1.8 \mathrm{~m}$ shielded DC cables is used in the system. To discuss the influences of DC cable type on system CM EMI noise, systems with $1.8 \mathrm{~m}$ shielded DC cables and $1.8 \mathrm{~m}$ unshielded DC cables are simulated, respectively. A bunch of $1.6 \mathrm{~m}$ shielded AC cables is used in the system. In addition, when shielded AC cables are used, two terminals of the shielding layers are connected to the inverter chassis and the PMSM frame, respectively. Similar, when shielded DC cables are used, two terminals of the shielding layers are connected to the inverter chassis and the LISN chassis, respectively. The CM LISN voltage $V_{\text {LISN }}$ is the arithmetic average of the voltages on the $50 \Omega$ resistors installed on the LISNs. The spectral of $V_{\text {LISN }}$ are calculated through the Fourier series.

\section{A. AC Cable Length}

Fig. 11 shows the simulation amplitude spectral envelopes of $V_{\text {LISN }}$ of powertrains with $1.6 \mathrm{~m}$ and $4.8 \mathrm{~m}$ shielded AC cables. The amplitude spectral envelopes of $V_{\text {LISN }}$ of a powertrain with short shielded AC cables is lower in low frequency range and

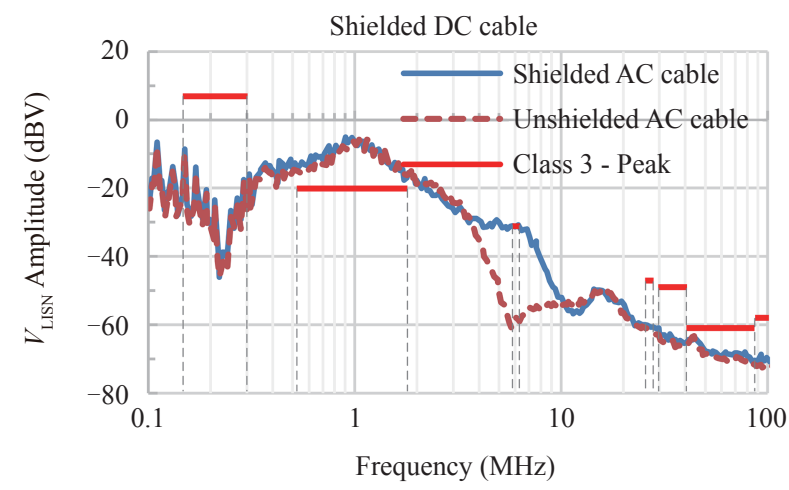

(a)

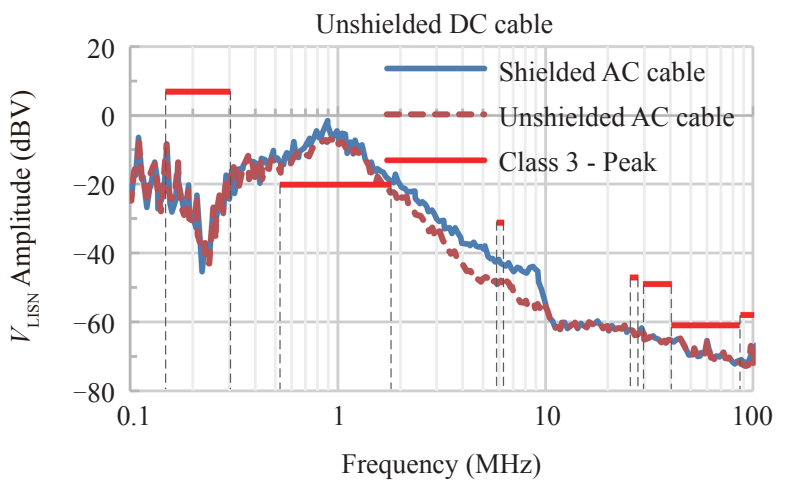

(b)

Fig. 12. Simulation amplitude spectral envelopes of $V_{\text {LISN }}$ Vs. AC cable type (a) a systems with $1.8 \mathrm{~m}$ shielded DC cables and $1.6 \mathrm{~m}$ shielded AC cables vs. a systems with $1.8 \mathrm{~m}$ shielded DC cables and $1.6 \mathrm{~m}$ unshielded AC cables, and (b) a systems with $1.8 \mathrm{~m}$ unshielded DC cables and $1.6 \mathrm{~m}$ unshielded AC cables vs. a systems with $1.8 \mathrm{~m}$ unshielded DC cables and $1.6 \mathrm{~m}$ unshielded AC cables.

is higher in high frequency range than that of a powertrain with long shielded AC cables. When the $4.8 \mathrm{~m}$ shielded AC cables are replaced by the $1.6 \mathrm{~m}$ shielded $\mathrm{AC}$ cables, the amplitude peak of $V_{\text {LISN }}$ spectra reduces about $10 \mathrm{dBV}$.

\section{B. Shielded AC Cable and Unshielded AC Cable}

Fig. 12(a) shows the simulation amplitude spectral envelopes of $V_{\text {LISN }}$ for systems with shielded AC cables and unshielded AC cables when shielded DC cables are used in both of the systems. The amplitude spectral envelopes of $V_{\text {LISN }}$ are almost equal in the frequency range of $150 \mathrm{kHz}-4 \mathrm{MHz}$ and 9-108 MHz between the two systems. However, the system with shielded DC cables and unshielded AC cables has much lower CM noise (with a maximum value of $30 \mathrm{dBV}$ ) in the frequency range of 4-9 MHz. Fig. 12(b) shows the simulation results for systems with shielded AC cables and unshielded AC cables when unshielded DC cables are used. The amplitude spectral envelope of $V_{\text {LISN }}$ of the system with unshielded DC and $\mathrm{AC}$ cables is lower (with a maximum value of $12 \mathrm{dBV}$ ) in the frequency range of 2-9 MHz. It can be seen that no matter shielded DC cables or unshielded DC cables are used, the amplitude spectral envelopes of $V_{\text {LISN }}$ of the system with 


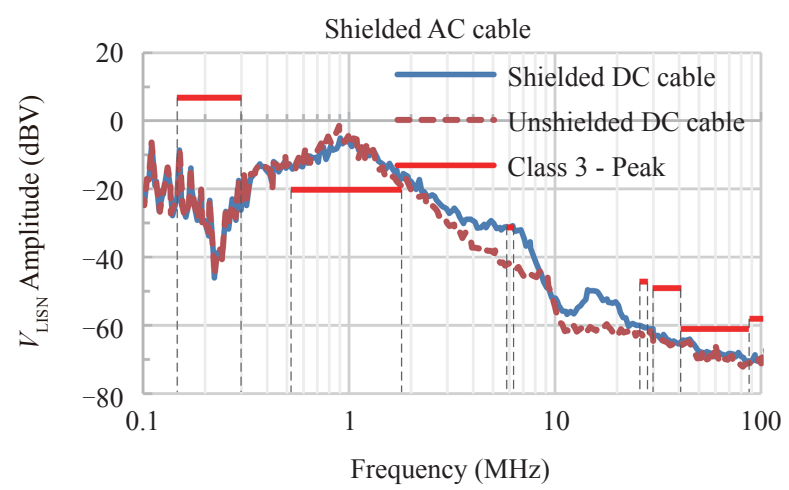

(a)

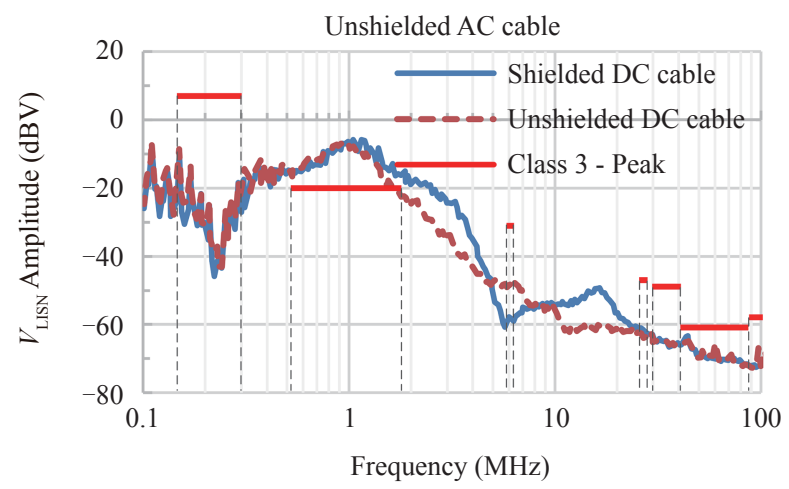

(b)

Fig. 13. Simulation amplitude spectral envelopes of $V_{\text {LISN }}$ vs. DC cable type (a) a systems with $1.8 \mathrm{~m}$ shielded DC cables and $1.6 \mathrm{~m}$ shielded AC cables vs. a systems with $1.8 \mathrm{~m}$ unshielded DC cables and $1.6 \mathrm{~m}$ shielded AC cables, and (b) a systems with $1.8 \mathrm{~m}$ shielded DC cables and $1.6 \mathrm{~m}$ unshielded AC cables vs. a systems with $1.8 \mathrm{~m}$ unshielded DC cables and $1.6 \mathrm{~m}$ unshielded AC cables.

unshielded AC cables is low.

\section{Shielded DC Cable and Unshielded DC Cable}

Fig. 13(a) shows the simulation amplitude spectral envelopes of $V_{\text {LISN }}$ for systems with shielded DC cables and unshielded DC cables when shielded AC cables are used in both of the systems. The amplitude spectral envelopes of $V_{\text {LISN }}$ are almost equal in the frequency range of $150 \mathrm{kHz}-3 \mathrm{MHz}$ and $20-108 \mathrm{MHz}$ between the two systems. However, the system with unshielded DC cables and shielded AC cables has lower CM noise (with a maximum value of $12 \mathrm{dBV}$ ) in the frequency range of 3-8 MHz and 10-20 MHz. Fig. 13(b) shows the simulation amplitude spectral envelopes of $V_{\text {LISN }}$ for systems with shielded DC cables and unshielded DC cables when unshielded AC cables are used in both of the systems. The amplitude spectral envelope of $V_{\text {LISN }}$ of the system with unshielded DC and AC cables is lower (with a maximum value of $15 \mathrm{dBV}$ ) in the frequency range of $1.5-5 \mathrm{MHz}$ and $10-20 \mathrm{MHz}$, but is higher (with a maximum value of $10 \mathrm{dBV}$ ) in the frequency range of 5-8 MHz. It can be seen that using unshielded DC cables when shielded AC cables are used can reduced the amplitude spectral envelope of $V_{\text {LISN }}$ in the full frequency range.

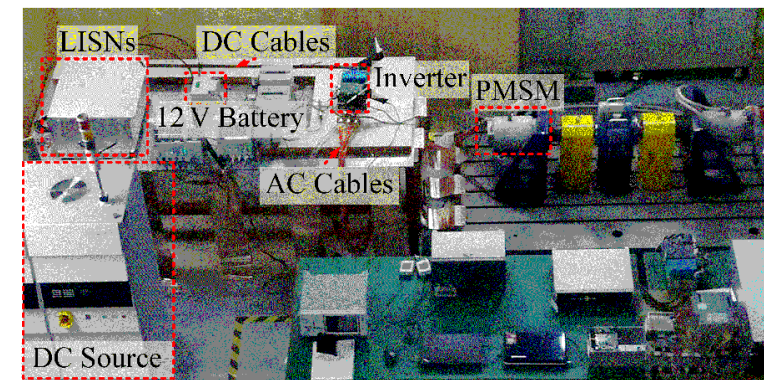

Fig. 14. A conducted emission test platform for an EV powertrain.

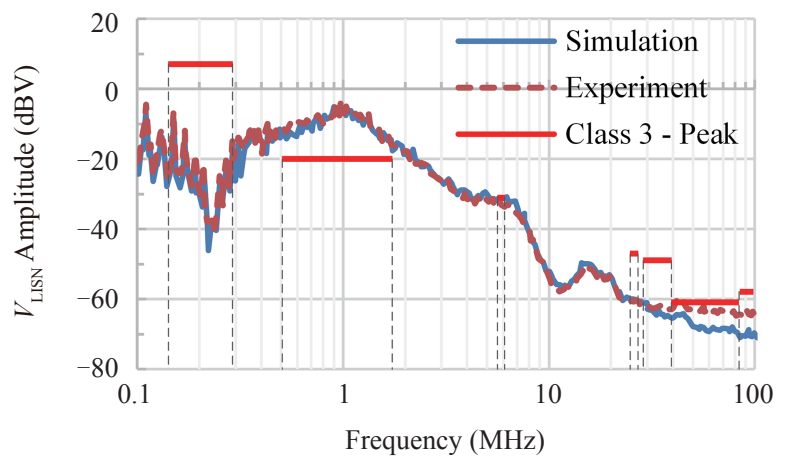

Fig. 15. Experimental and simulation amplitude spectral envelopes of $V_{\text {LISN }}$.

\section{EXPERIMENT VERIFICATION}

Fig. 14 shows a conducted emission test platform for an EV powertrain, which was built based on the IEC international standard CISPR 25, 2016 [34]. The DC source (Chroma 17040) simulates a battery pack and supplies DC voltage. A $12 \mathrm{~V}, 100$ Ah lead-acid battery is used as a low voltage auxiliary power supply of the inverter. The LISN chassis, inverter chassis, and frame of the PMSM are connected to the ground plane. All of the tests are carried out at the same inverter operation point, which has been listed in Table V. The inverter operates under continuous SVPWM. The LISN voltages are measured by an oscilloscope, the spectral of $V_{\text {LISN }}$ is calculated through the Fourier series.

To verify the system-level EMI model, experiments were carried out on the conducted EMI test platform of a SiC EV powertrain. Fig. 15 shows the experimental and simulation amplitude spectral envelopes of $V_{\text {LISN }}$. The experimental amplitude spectral envelope of $V_{\text {LISN }}$ matches the simulation amplitude spectral envelope well in the frequency range of $150 \mathrm{kHz}-40 \mathrm{MHz}$. However, the experimental results are about $6 \mathrm{dBV}$ higher than the simulation results in the frequency range of 40-108 MHz. There are two possible reasons for the error between the simulation and experimental results in high frequency range. First, in the presented model, switching ringing of drain-source voltages is ignored in the simulation model, which enhances the high frequency EMI noise [12], [15]. As a result, the simulation amplitude spectral envelope of $V_{\text {LISN }}$ is undervalued in high frequency range. Second, at 


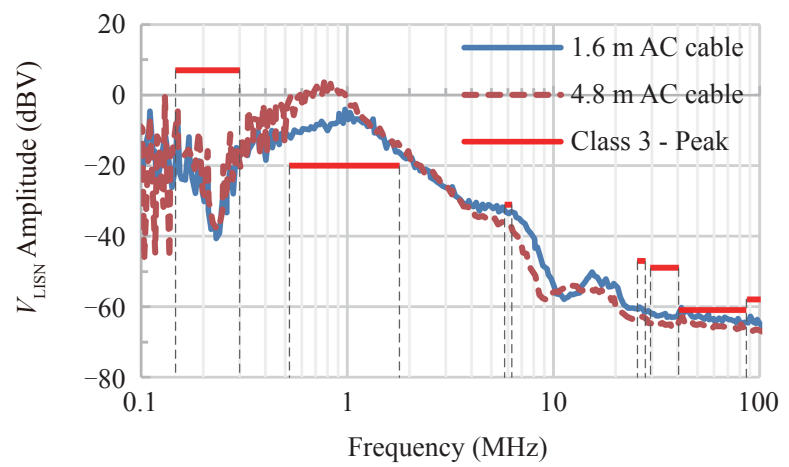

Fig. 16. Experimental amplitude spectral envelopes of $V_{\text {LISN }}$ of systems with $1.6 \mathrm{~m}$ and $4.8 \mathrm{~m}$ shielded AC cables.

frequencies higher than $30 \mathrm{MHz}$, the experimental amplitude spectral envelope of $V_{\text {LISN }}$ is lower than $-60 \mathrm{dBV}(1 \mathrm{mV})$, which is sensitive to measurement accuracy.

With respect to the influence of AC cable length, Fig. 16 shows the experimental amplitude spectral envelopes of $V_{\text {LISN }}$ of powertrains with $1.6 \mathrm{~m}$ shielded AC cables and $4.8 \mathrm{~m}$ shielded AC cables. The amplitude spectral envelopes of $V_{\text {LISN }}$ of a system with $1.6 \mathrm{~m}$ shielded AC cables is lower in low frequency range (including the amplitude peak frequency) and is higher in high frequency range than that of the system with $4.8 \mathrm{~m}$ shielded cables. Replacing the $4.8 \mathrm{~m}$ shielded AC cable by the $1.6 \mathrm{~m}$ shielded AC cables, the amplitude spectral envelope of $V_{\text {LISN }}$ reduces about $10 \mathrm{dBV}$ in the frequency range of $150-900 \mathrm{kHz}$, and increases about 4-10 dBV in the frequency range of 4-9 $\mathrm{MHz}$.

With respect to the impact of AC cable type, experimental amplitude spectral envelopes of $V_{\text {LISN }}$ for systems with shielded AC cables and unshielded AC cables are compared. The experimental results are shown in Fig. 17(a) when shielded DC cables are used in both of the systems. In this case, the amplitude spectral envelope of $V_{\text {LISN }}$ of the system with unshielded AC cables is almost the same as that of the system with shielded AC cables in the frequency range of $150 \mathrm{kHz}-$ $4 \mathrm{MHz}$ and 9-108 MHz. However, it reduces significantly (the maximum reduction is $27 \mathrm{dBV}$ ) in the frequency range of 4-9 MHz. In Fig. 17(b), both of the systems use unshielded DC cables. In this case, the amplitude spectral envelope of $V_{\text {LISN }}$ of the system with unshielded AC cables is much lower (the maximum difference is $15 \mathrm{dBV}$ ) than that of the system with shielded AC cables. Hence, the system with unshielded AC cables has low CM LISN voltage no matter shielded DC cables or unshielded DC cables are used.

With respect to the influence of DC cable type, Fig. 18 shows the experimental amplitude spectral envelopes of $V_{\text {LISN }}$ for systems with shielded DC cables and unshielded DC cables. Shielded AC cables are used in both of the system. The system with unshielded DC cables has low CM LISN voltage. The amplitude spectral envelope of $V_{\text {LISN }}$ of the system with unshielded DC cables is $4-10 \mathrm{dBV}$ lower in the frequency

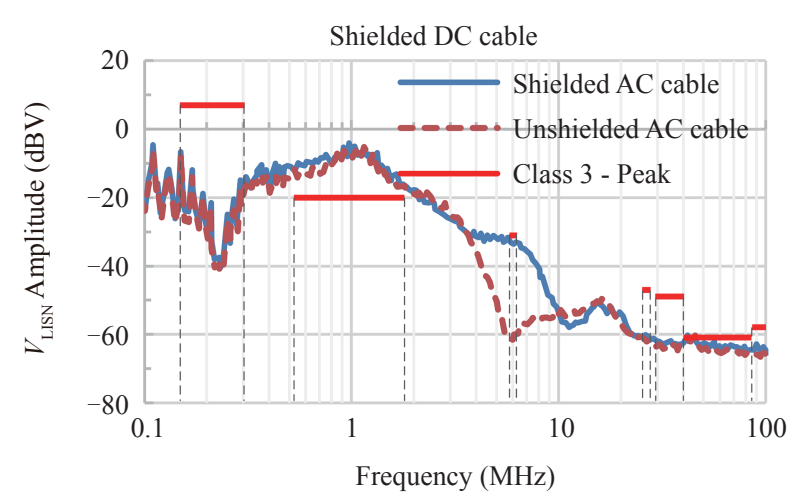

(a)

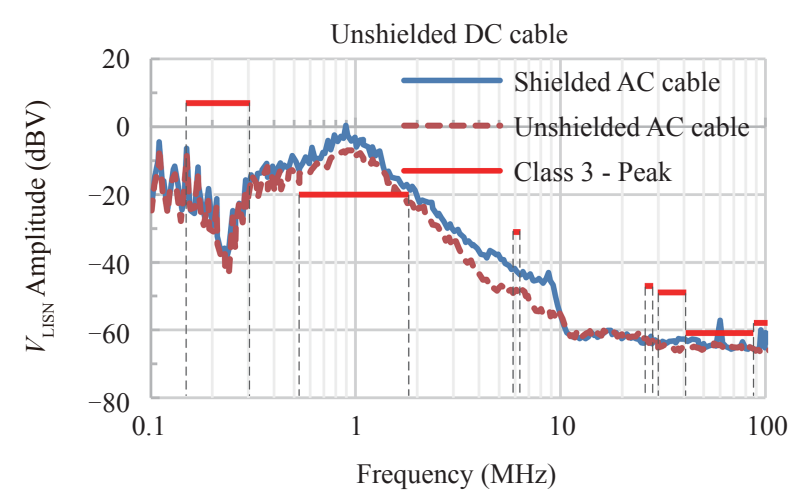

(b)

Fig. 17. Experimental amplitude spectral envelopes of $V_{\text {LISN }}$ VS. AC cable type (a) a system with $1.6 \mathrm{~m}$ shielded DC cables and $1.8 \mathrm{~m}$ shielded AC cables vs. a system with $1.8 \mathrm{~m}$ shielded DC cables and $1.6 \mathrm{~m}$ unshielded AC cables, and (b) a system with $1.8 \mathrm{~m}$ unshielded DC cables and $1.6 \mathrm{~m}$ shielded AC cables vs. a system with $1.8 \mathrm{~m}$ unshielded DC cables and $1.6 \mathrm{~m}$ unshielded AC cables.

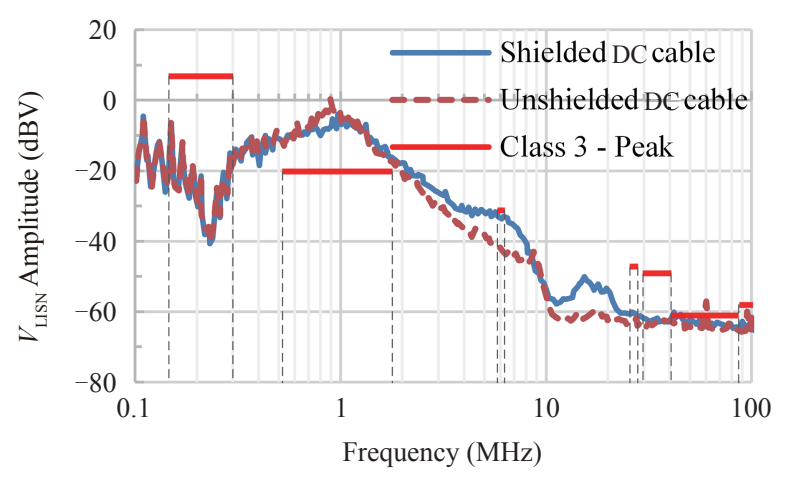

Fig. 18. Experimental amplitude spectral envelopes of $V_{\text {LISN }}$ for a system with $1.8 \mathrm{~m}$ shielded DC cables and $1.6 \mathrm{~m}$ shielded AC cables and a system with $1.8 \mathrm{~m}$ unshielded DC cables and $1.6 \mathrm{~m}$ shielded AC cables.

range of 3-8 MHz and 10-20 MHz than that of the system with shielded DC cables.

\section{CONCLUSION}

In this paper, the influences of system layout, such as $\mathrm{AC}$ cable length, AC cable type, and DC cable type on CM EMI 
noise of a $\mathrm{SiC} \mathrm{EV}$ powertrain were investigated. With respect to AC cable length, spectra of CM LISN voltage with short $\mathrm{AC}$ cables has low amplitude peak. In the prototype, the amplitude peak of $V_{\text {LISN }}$ of a system with $1.6 \mathrm{~m}$ shielded $\mathrm{AC}$ cables reduces about $10 \mathrm{dBV}$ than that of a system with $4.8 \mathrm{~m}$ shielded AC cables. With respect to AC cable type, a system with unshielded AC cables has lower CM noise on LISN voltage no matter shielded DC cables or unshielded DC cables are used. In the prototype, when shielded DC cables are used, the maximum reduction of $V_{\text {LISN }}$ amplitude spectral envelope is $27 \mathrm{dBV}$ in the frequency range of $4-9 \mathrm{MHz}$ in the system with unshielded AC cables. When unshielded DC cables are used, the maximum reduction of $V_{\text {LISN }}$ amplitude spectral envelope is $12 \mathrm{dBV}$ in the frequency range of $2-10 \mathrm{MHz}$ in the system with unshielded AC cables. With respect to DC cable type, a system with unshielded DC cables has lower CM noise on LISN voltage when shielded AC cables are used. In the prototype, the maximum reduction of $V_{\text {LISN }}$ amplitude spectral envelope is $10 \mathrm{dBV}$ in the frequency range of 3-8 MHz and 10-20 MHz in the system with unshielded DC cables.

\section{APPENDIX}

\section{A. CM Noise Source}

In the AC side, since the PWM modulation for a three-phase inverter is symmetric, $v_{\mathrm{AN}}, v_{\mathrm{BN}}$ and $v_{\mathrm{CN}}$ are shifted $120^{\circ}$ between each other. Therefore, $V_{\mathrm{BN}}(n)$ and $V_{\mathrm{CN}}(n)$ can be expressed as follows:

$$
\left\{\begin{array}{l}
V_{\mathrm{BN}}(n)=V_{\mathrm{AN}}(n) \mathrm{e}^{-j n \frac{2 \pi}{3}} \\
V_{\mathrm{CN}}(n)=V_{\mathrm{AN}}(n) \mathrm{e}^{-j n \frac{4 \pi}{3}}
\end{array}\right.
$$

Substituting (5) into (1) yields:

$$
V_{\mathrm{CM} 0}(n)=\frac{1+\mathrm{e}^{-j n \frac{2 \pi}{3}}+\mathrm{e}^{-j n \frac{4 \pi}{3}}}{3} V_{\mathrm{AN}}(n)
$$

For zero sequences, $n=3 m, m=1,2, \ldots$, (6) can be simplified:

$$
V_{\mathrm{CM} 0}(n)=V_{\mathrm{AN}}(n)=V_{\mathrm{BN}}(n)=V_{\mathrm{CN}}(n)
$$

For positive sequences, $n=3 m+1, m=1,2, \ldots,(6)$ can be simplified:

$$
V_{\mathrm{CM} 0}(n)=0
$$

For negative sequences, $n=3 m+2, m=1,2, \ldots,(6)$ can be simplified:

$$
V_{\mathrm{CM} 0}(n)=0
$$

It can be seen that the zero sequences generate CM noise, whereas the positive sequences and the negative sequences do not generate $\mathrm{CM}$ noise. In addition, CM components (zero sequences) of $v_{\mathrm{AN}}, v_{\mathrm{BN}}$ and $v_{\mathrm{CN}}$ are the same according to (7). As a result, inverter $\mathrm{AC}$ terminals of node $A$, node $B$, and node $C$ can be short connected in $\mathrm{CM}$ noise analysis.

\section{B. Cable Parameters}

\section{1) Shielded Cables}

The p.u.l self-inductance of a cable core and the p.u.l selfinductance of a cable shield [23] are expressed as follows:

$$
\left\{\begin{array}{l}
L_{\mathrm{c}}=\frac{\mu_{0}}{2 \pi} \ln \left(\frac{2 h}{r_{\mathrm{c}}}\right), \\
L_{\mathrm{s}}=\frac{\mu_{0}}{2 \pi} \ln \left(\frac{2 h}{r_{\mathrm{s}}}\right)
\end{array}\right.
$$

where $\mu_{0}$ is the vacuum permeability, $h$ is the height of the cable above the ground plane, $r_{\mathrm{c}}$ is the radius of the cable core of the shielded and unshielded cables, $r_{\mathrm{s}}$ is the radius of the cable shield.

The mutual inductance between the shield and the inner conductor of any cable is taken to be equal to the self-inductance of the cable shield $L_{\mathrm{s}}$ [23].

The mutual inductance between the cores of one cable and another cable, the mutual inductance between the shields of one cable and another cable, and the mutual inductance between the core of one cable and the shield of another cable are the same, which is expressed [23] as follows:

$$
L_{\mathrm{m}}=\frac{\mu_{0}}{4 \pi} \ln \left(1+\frac{4 h^{2}}{s^{2}}\right)
$$

where $s$ is the distance between the centers of the cores of both cables.

The p.u.l capacitance between the core and the shield of any cable is expressed [35] as follows:

$$
C_{\mathrm{cs}}=\frac{2 \pi \varepsilon_{r}}{\ln \left(\frac{r_{\mathrm{s}}}{r_{\mathrm{c}}}\right)}
$$

where $\varepsilon_{\mathrm{r}}$ is the dielectric constant of the cable insulation layer.

\section{2) Unshielded Cables}

The p.u.l self-inductance of an unshielded cable core is equal to the expression of $L_{\mathrm{c}}$ in (10).

The p.u.l mutual inductance between cores of one unshielded cable and another one is equal to the expression of $L_{\mathrm{m}}$ in (11).

The p.u.l capacitance between the unshielded cable core and the ground plane is expressed [35] as follows:

$$
C_{\mathrm{cg}} \approx \frac{2 \pi \varepsilon_{0}}{\ln \left(\frac{2 h}{r_{\mathrm{c}}}\right)}
$$




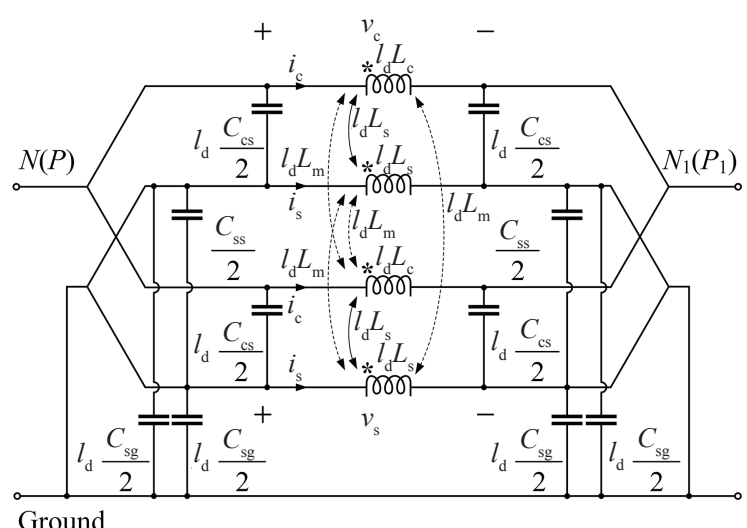

(a)

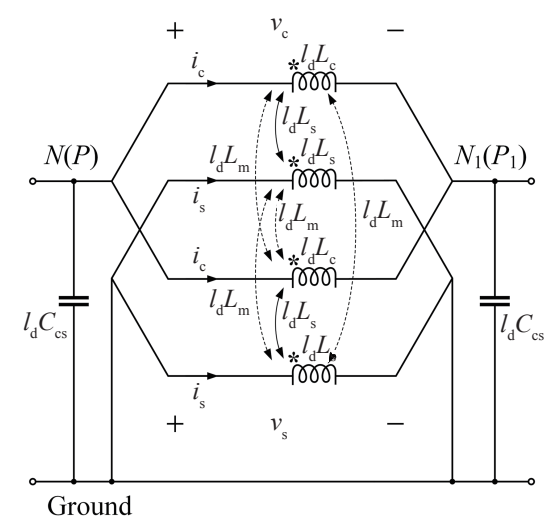

(b)

Fig. 19. Shielded DC cable model (a) lumped circuit model, and (b) an equivalent circuit.

\section{Parameters of Cable's Lumped Circuit}

\section{1) Shielded DC Cables}

For shielded DC cables, cores of the two cables are shorted at both the inverter side and the LISN side according to the analysis in Section II. In addition, shields of the two cables are short-circuited to the ground plane at both the inverter side and the LISN side. According to the multiconductor transmission line theory, the lumped circuit model of shielded DC cables is shown in Fig. 19(a). Fig. 19(b) shows an equivalent circuit of the shielded DC cables.

Obviously, the equivalent capacitance is expressed as follows:

$$
C_{\mathrm{dg}(s)}=2 l_{\mathrm{d}} C_{\mathrm{cs}}
$$

The voltage of cable core and cable shield are expressed as follows:

$$
\left\{\begin{array}{l}
V_{\mathrm{c}}=s l_{\mathrm{d}} L_{\mathrm{c}} I_{\mathrm{c}}+s l_{\mathrm{d}} L_{\mathrm{s}} I_{\mathrm{s}}+s l_{\mathrm{d}} L_{\mathrm{m}} I_{\mathrm{c}}+s l_{\mathrm{d}} L_{\mathrm{m}} I_{\mathrm{s}} \\
V_{\mathrm{s}}=s l_{\mathrm{d}} L_{\mathrm{s}} I_{\mathrm{s}}+s l_{\mathrm{d}} L_{\mathrm{s}} I_{\mathrm{c}}+s l_{\mathrm{d}} L_{\mathrm{m}} I_{\mathrm{c}}+s l_{\mathrm{d}} L_{\mathrm{m}} I_{\mathrm{s}}
\end{array}\right.
$$

For the reason that cable shields are shorted by the ground plane, we have $V_{\mathrm{s}}=0$. Substituting it into $V_{\mathrm{s}}$ expression in (15)

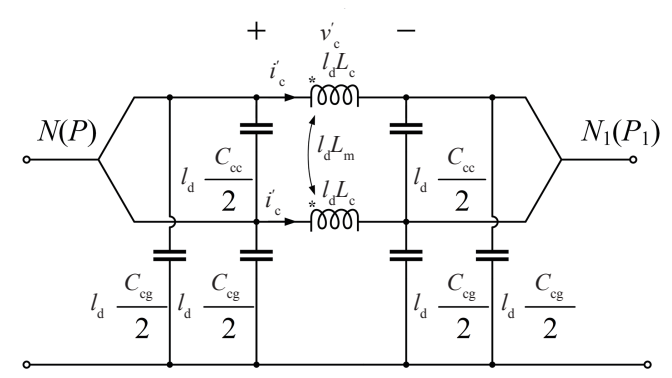

(a)

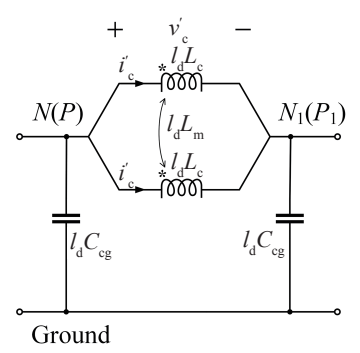

(b)

Fig. 20. Unshielded DC cable model (a) lumped circuit model, and (b) an equivalent circuit.

yields:

$$
I_{\mathrm{s}}=-I_{\mathrm{c}}
$$

Substituting (16) into $V_{\mathrm{c}}$ expression in (15) yields:

$$
V_{\mathrm{c}}=s \cdot l_{\mathrm{d}} \frac{L_{\mathrm{c}}-L_{\mathrm{s}}}{2} \cdot 2 I_{\mathrm{c}}
$$

So, the equivalent inductance of shielded DC cables is expressed as follows:

$$
L_{\mathrm{d}(\mathrm{s})}=l_{\mathrm{d}} \frac{L_{\mathrm{c}}-L_{\mathrm{s}}}{2}
$$

\section{2) Unshielded DC Cables}

Fig. 20(a) shows the lumped circuit model of unshielded DC cables. Fig. 20(b) shows an equivalent circuit of unshielded DC cables.

The equivalent capacitance is expressed as follows:

$$
C_{\mathrm{dg}(\mathrm{u})}=2 l_{\mathrm{d}} C_{\mathrm{cg}}
$$

The voltage of cable core is expressed as follows:

$$
\begin{aligned}
V_{\mathrm{c}}^{\prime} & =s l_{\mathrm{d}} L_{\mathrm{c}} I_{\mathrm{c}}^{\prime}+s l_{\mathrm{d}} L_{\mathrm{m}} I_{\mathrm{c}}^{\prime} \\
& =s \cdot l_{\mathrm{d}} \frac{L_{\mathrm{c}}+L_{\mathrm{m}}}{2} \cdot 2 I_{\mathrm{c}}^{\prime}
\end{aligned}
$$

So, the equivalent inductance of shielded DC cables is:

$$
L_{\mathrm{d}(\mathrm{u})}=l_{\mathrm{d}} \frac{L_{\mathrm{c}}+L_{\mathrm{m}}}{2}
$$




\section{3) Shielded AC Cables and Unshielded AC Cables}

Similar to the derivation of equivalent inductance and capacitance for shielded DC cables and unshielded DC cables, the equivalent capacitances of shielded $\mathrm{AC}$ cables and unshielded AC cables are expressed as follows:

$$
\left\{\begin{array}{l}
C_{\mathrm{ag}(\mathrm{s})}=3 l_{\mathrm{a}} C_{\mathrm{cs}}, \\
C_{\mathrm{ag}(\mathrm{u})}=3 l_{\mathrm{a}} C_{\mathrm{cg}}
\end{array}\right.
$$

The equivalent inductances of shielded $\mathrm{AC}$ cables and unshielded AC cables are expressed as follows:

$$
\left\{\begin{array}{l}
L_{\mathrm{a}(\mathrm{s})}=l_{\mathrm{a}} \frac{L_{\mathrm{c}}-L_{\mathrm{s}}}{3}, \\
L_{\mathrm{a}(\mathrm{u})}=l_{\mathrm{a}} \frac{L_{\mathrm{c}}+2 L_{\mathrm{m}}}{3}
\end{array}\right.
$$

\section{ACKNOWLEDGMENT}

This work is partially supported by Bosch Company. The authors would like to acknowledge the kind support of Dr. Alexander Boronka, Dr. Yanlin Li, and Dr. Maojun He of Bosch Company and Dr. Leo Lorenz of European Center of Power Electronics for their constructive suggestions and cooperation.

\section{REFERENCES}

[1] J. Biela, M. Schweizer, S. Waffler, and J. W. Kolar, "SiC versus $\mathrm{Si}-$ evaluation of potentials for performance improvement of inverter and DC-DC converter systems by $\mathrm{SiC}$ power semiconductors," in IEEE Transactions on Industrial Electronics, vol. 58, no. 7, pp. 2872-2882, Jul. 2011.

[2] D. Han, J. Noppakunkajorn, and B. Sarlioglu, "Comprehensive efficiency, weight, and volume comparison of SiC- and Si-based bidirectional DC-DC converters for hybrid electric vehicles," in IEEE Transactions on Vehicular Technology, vol. 63, no. 7, pp. 3001-3010, Sept. 2014.

[3] Z. Zhang, F. Wang, L. M. Tolbert, B. J. Blalock, and D. J. Costinett, "Evaluation of switching performance of $\mathrm{SiC}$ devices in PWM inverterfed induction motor drives," in IEEE Transactions on Power Electronics, vol. 30, no. 10, pp. 5701-5711, Oct. 2015.

[4] F. Wang and Z. Zhang, "Overview of silicon carbide technology: Device, converter, system, and application," in CPSS Transactions on Power Electronics and Applications, vol. 1, no. 1, pp. 13-32, Dec. 2016.

[5] Mitsubishi Electric Corporation. Mitsubishi Electric Develops EV Motor Drive System with Built-in Silicon Carbide Inverter. Accessed: May. 1, 2020. [Online]. Available: http://www.mitsubishielectric.com/ news/2014/pdf/0213-d.pdf

[6] About The SiC MOSFETs Modules in Tesla Model 3. Accessed: May. 1, 2019. [Online]. Available: https://www.pntpower.com/tesla-model-3powered-by-st-microelectronics-sic-mosfets/

[7] F. Luo, S. Wang, F. Wang, D. Boroyevich, N. Gazel, Y. Kang, and A. C. Baisden, "Analysis of CM volt-second influence on $\mathrm{CM}$ inductor saturation and design for input EMI filters in three-phase DC-fed motor drive systems," in IEEE Transactions on Power Electronics, vol. 25, no. 7, pp. 1905-1914, Jul. 2010.

[8] H. Bishnoi, P. Mattavelli, R. Burgos, and D. Boroyevich, "EMI behavioral models of DC-fed three-phase motor drive systems," in IEEE Transactions on Power Electronics, vol. 29, no. 9, pp. 4633-4645, Sept. 2014.

[9] J. Sun and L. Xing, "Parameterization of three-phase electric machine models for EMI simulation," in IEEE Transactions on Power Electronics, vol. 29, no. 1, pp. 36-41, Jan. 2014.
[10] N. Mutoh, M. Nakanishi, M. Kanesaki, and J. Nakashima, "EMI noise control methods suitable for electric vehicle drive systems," in IEEE Transactions on Electromagnetic Compatibility, vol. 47, no. 4, pp. 930-937, Nov. 2005.

[11] D. Han, S. Li, Y. Wu, W. Choi, and B. Sarlioglu, "Comparative analysis on conducted CM EMI emission of motor drives: WBG versus Si devices," in IEEE Transactions on Industrial Electronics, vol. 64, no. 10, pp. 8353-8363, Oct. 2017.

[12] Z. Fang, D. Jiang, and Y. Zhang, "Study of the characteristics and suppression of EMI of inverter with $\mathrm{SiC}$ and $\mathrm{Si}$ devices," in Chinese Journal of Electrical Engineering, vol. 4, no. 3, pp. 37-46, Sept. 2018.

[13] N. Oswald, B. H. Stark, D. Holliday, C. Hargis, and B. Drury, "Analysis of shaped pulse transitions in power electronic switching waveforms for reduced EMI generation," in IEEE Transactions on Industry Applications, vol. 47, no. 5, pp. 2154-2165, Sept.-Oct. 2011.

[14] N. Oswald, P. Anthony, N. McNeill, and B. H. Stark, "An experimental investigation of the tradeoff between switching losses and EMI generation with hard-switched $\mathrm{All}-\mathrm{Si}, \mathrm{Si}-\mathrm{SiC}$, and All-SiC device combinations," in IEEE Transactions on Power Electronics, vol. 29, no. 5, pp. 2393-2407, May 2014.

[15] K. Oberdieck, A. Sewergin, and R. W. De Doncker, "Influence of the voltage-dependent output capacitance of $\mathrm{SiC}$ semiconductors on the electromagnetic interference in DC-DC converters for electric vehicles," in Proceedings of 2017 International Symposium on Electromagnetic Compatibility - EMC EUROPE, Angers, France, 2017, pp. 1-6.

[16] D. Zhang, L. Kong, and X. Wen, "High frequency model of interior permanent magnet motor for EMI analysis," in Proceedings of 2014 IEEE Conference and Expo Transportation Electrification Asia-Pacific (ITEC Asia-Pacific), Beijing, China, 2014, pp. 1-6.

[17] K. Gulez and A. A. Adam, "High-frequency common-mode modeling of permanent magnet synchronous motors," in IEEE Transactions on Electromagnetic Compatibility, vol. 50, no. 2, pp. 423-426, May 2008.

[18] Y. Kwack, H. Kim, C. Song, M. Moon, D. -H. Kim, B. Kim, E. Kim, and J. Kim, "EMI modeling method of interior permanent magnet synchronous motor for hybrid electric vehicle drive system considering parasitic and dynamic parameters," in Proceedings of 2015 Asia-Pacific Symposium on Electromagnetic Compatibility (APEMC), Taipei, Taiwan, China, 2015, pp. 78-81.

[19] O. A. Mohammed, S. Ganu, N. Abed, S. Liu, and Z. Liu, "High frequency PM synchronous motor model determined by FE analysis," in IEEE Transactions on Magnetics, vol. 42, no. 4, pp. 1291-1294, Apr. 2006.

[20] J. Luszcz, "AC motor feeding cable consequences on EMC performance of ASD," in Proceedings of 2013 IEEE International Symposium on Electromagnetic Compatibility, Denver, CO, USA, 2013, pp. 248-252.

[21] R. M. Tallam, G. L. Skibinski, T. A. Shudarek, and R. A. Lukaszewski, "Integrated differential-mode and common-mode filter to mitigate the effects of long motor leads on AC drives," in IEEE Transactions on Industry Applications, vol. 47, no. 5, pp. 2075-2083, Sept--Oct. 2011.

[22] A. Kishore, C. Patki, M. Anwar, W. Ivan, and M. Teimor, "Investigation of common mode noise in electric propulsion system high voltage components in an electrified vehicle," in Proceedings of 2016 IEEE Transportation Electrification Conference and Expo (ITEC), Dearborn, MI, USA, 2016, pp. 1-6.

[23] M. S. Murthy and G. A. Rasek, "Analytical determination of current distributions in shielded HV cables and ground systems of electric automotive power trains," in IEEE Transactions on Electromagnetic Compatibility, vol. 61, no. 3, pp. 911-918, Jun. 2019.

[24] G. Spadacini, F. Grassi, and S. A. Pignari, "Generation and propagation of radio frequency noise currents in the powertrain of electric vehicles," in Proceedings of 2016 IEEE Vehicle Power and Propulsion Conference (VPPC), Hangzhou, China, 2016.

[25] S. Yun, J. Ha, M. Kim, C. Lee, Y. Kim, and J. Yoo, "Integrated modeling of a motor driven system for analysis of conducted emissions," in Proceedings of 2016 International Symposium on Electromagnetic Compatibility - EMC EUROPE, Wroclaw, Poland, 2016, pp. 850-854.

[26] Y. Maillet, R. Lai, S. Wang, F. Wang, R. Burgos, and D. Boroyevich, "High-density EMI filter design for DC-fed motor drives," in IEEE Transactions on Power Electronics, vol. 25, no. 5, pp. 1163-1172, May 2010.

[27] S. Wang, Y. Y. Maillet, F. Wang, D. Boroyevich, and R. Burgos, "Investigation of hybrid EMI filters for common-mode EMI suppression 
in a motor drive system," in IEEE Transactions on Power Electronics, vol. 25, no. 4, pp. 1034-1045, Apr. 2010.

[28] M. C. Di Piazza, M. Luna, and G. Vitale, "EMI reduction in DCfed electric drives by active common-mode compensator," in IEEE Transactions on Electromagnetic Compatibility, vol. 56, no. 5, pp. 1067-1076, Oct. 2014.

[29] L. Xing and J. Sun, "Conducted common-mode EMI reduction by impedance balancing," in IEEE Transactions on Power Electronics, vol. 27, no. 3, pp. 1084-1089, Mar. 2012.

[30] R. Chen, Z. Zhang, R. Ren, J. Niu, H. Gui, F. Wang, L. M. Tolbert, D. J. Costinett, and B. J. Blalock, "Common-mode noise reduction with impedance balancing in DC-fed motor drives," in Proceedings of 2018 IEEE Applied Power Electronics Conference and Exposition (APEC), San Antonio, TX, USA, 2018, pp. 2515-2520.

[31] X. Jia, C. Hu, B. Dong, F. He, H. Wang, and D. Xu, "System-level conducted EMI model for $\mathrm{SiC}$ powertrain of electric vehicles," in Proceedings of 2020 IEEE Applied Power Electronics Conference and Exposition (APEC), New Orleans, LA, USA, 2020, pp. 885-892.

[32] L. Yang, H. Zhao, S. Wang, and Y. Zhi, "Common-mode EMI noise analysis and reduction for AC-DC-AC systems with paralleled power modules," in IEEE Transactions on Power Electronics, vol. 35, no. 7, pp. 6989-7000, Jul. 2020.

[33] M. R. Ahmed, R. Todd, and A. J. Forsyth, "Predicting SiC MOSFET behavior under hard-switching, soft-switching, and false turn-on conditions," in IEEE Transactions on Industrial Electronics, vol. 64, no. 11, pp. 9001-9011, Nov. 2017.

[34] International Electrotechnical Commission: Vehicles, boats and internal combustion engines - Radio disturbance characteristics - Limits and methods of measurement for the protection of on-board receivers. CISPR 25, Geneva, Switzerland, 2016.

[35] C. R. Paul, "The per-unit-length parameters for two-conductor lines," in Analysis of Multiconductor Transmission Lines, 2nd ed., Hoboken, USA.

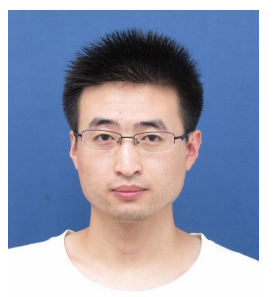

Xiaoyu Jia was born in Shanxi, China, in 1989. He received his B.S. degree in electrical engineering from Zhejiang University, Hangzhou, China, in 2011, where he is presently working towards his Ph.D. degree. His current research interests include power conversion and the conducted EMI emission of EV powertrains.

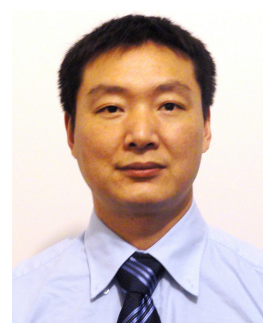

Changsheng Hu received his B.S. and M.S. degrees from Hefei University of Technology, Hefei, China, in 1995 and 1998, respectively. He received his Ph.D. degree from Zhejiang University, Hangzhou, China, in 2002.

$\mathrm{He}$ is presently working as an Associate Professor at Zhejiang University. His current research interests include power conversions for EVs, charging stations, renewable energy grid integration, energy-storage units, and the modeling and suppression of EMI.

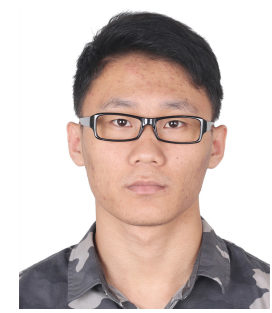

Bitao Dong received his B.S. degree in electrical engineering from Zhejiang University, Hangzhou, China, in 2019, where he is presently working towards his M.S. degree in power electronics.

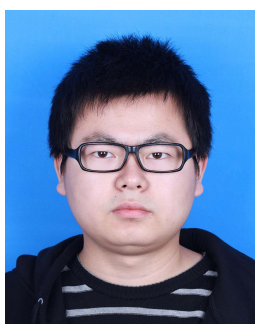

Fengchun He received the B.S. degree and M.S. degree in electrical engineering from Zhejiang University, Hangzhou, China in 2016 and 2019. Now he is an Electrical Engineer in Monolithic Power Systems, Inc., Hangzhou, China.

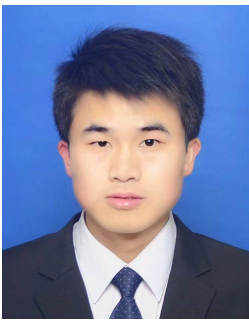

Hui Wang received his B.S. degree in hydropower and information engineering from Huazhong University of Science and Technology, Wuhan, China, in 2014. He is presently working towards his M.S. degree in power electronics at Zhejiang University, Hangzhou, China.

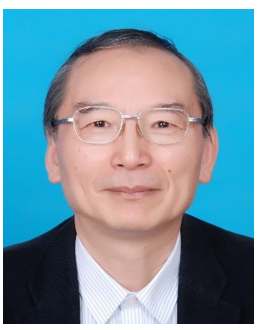

Dehong Xu was born in China, in 1961. He received his B.S., M.S., and Ph.D. degrees from the College of Electrical Engineering, Zhejiang University, Hangzhou, China, in 1983, 1986, and 1989, respectively.

Since 1996, he has been as a Full Professor in the College of Electrical Engineering, Zhejiang University. From June 1995 to May 1996, he was a Visiting Scholar at the University of Tokyo, Tokyo, Japan. From June to December 2000, he was a Visiting Professor in Center for Power Electronics Systems (CPES), Virginia Tech, Blacksburg, VA, USA. From February 2006 to April 2006, he was a Visiting Professor at the ETH, Switzerland. His current research interests include power electronics topologies and control, power conversion for renewable energy and energy saving. He has authored or coauthored eight books and more than 270 IEEE journal and conference papers. He holds more than 50 patents.

Dr. Xu was a recipient of seven IEEE journal and conference paper awards. He became an IEEE Fellow in 2013. He was an IEEE PELS Distinguish Lecturer from 2015 to 2017. He received an IEEE PELS R. D. Middlebrook Achievement Award in 2016. 